\title{
Synthesis, Crystal Structure, and Luminescence Properties of a New Calcium(II) Coordination Polymer Based on L-Malic Acid
}

\author{
Duraisamy Senthil Raja, ${ }^{1}$ Jheng-Hong Luo, ${ }^{1,2}$ Ting-Guang Chang, \\ Sheng-Han Lo, ${ }^{1}$ Cheng-You Wu, ${ }^{1}$ and Chia-Her Lin ${ }^{1}$ \\ ${ }^{1}$ Department of Chemistry, Chung Yuan Christian University, 200 Chung Pei Road, Chung Li 32023, Taiwan \\ ${ }^{2}$ Master Program in Nanotechnology, Chung Yuan Christian University, 200 Chung Pei Road, Chung Li 32023, Taiwan \\ Correspondence should be addressed to Chia-Her Lin; chiaher@cycu.edu.tw
}

Received 22 February 2013; Accepted 15 April 2013

Academic Editor: Jhy-Der Chen

Copyright (C) 2013 Duraisamy Senthil Raja et al. This is an open access article distributed under the Creative Commons Attribution License, which permits unrestricted use, distribution, and reproduction in any medium, provided the original work is properly cited.

\begin{abstract}
A new calcium coordination polymer $[\mathrm{Ca}(\mathrm{HL}-\mathrm{MA})]_{n}\left(\mathrm{H}_{3} \mathrm{~L}-\mathrm{MA}=\mathrm{L}-\right.$ malic acid $)$ has been solvothermally synthesized. The structure of the newly synthesized complex has been determined by single-crystal X-ray diffraction analysis and further characterized by elemental analysis, reflectance UV-Vis \& IR spectra, powder X-ray diffraction (PXRD), and thermogravimetric analysis (TGA). The single crystal structure analysis showed that the complex forms three-dimensional framework. The new Ca(II) complex has displayed very high thermal stability which was inferred from TGA and PXRD results. As far as the optical property of the new complex is concerned, the complex emitted its own characteristic sensitized luminescence.
\end{abstract}

\section{Introduction}

Multidimensional coordination polymers (CPs) or metalorganic frameworks (MOFs) which are derived from metal ions and organic ligands are emerged in the past two decades as an important family of porous materials with intriguing new structural topologies and potential application as functional materials [1-20]. In this regard, studies on the application aspects of MOFs such as ion exchange $[1,2]$, separation [3,4], gas storage [5], catalysis [6-9], sensor [10, $11]$, magnetism [12, 13], photoluminescence [14, 15], drug delivery $[16,17]$, and proton conduction $[18-20]$ are slowly developing. So, the synthesis and characterization of infinite one-, two-, and three-dimensional (1D, 2D, and 3D) networks has been an area of rapid growth. Apart from numerous application-oriented studies of CPs, considerable attention has also been devoted to their structures that were shown to change broadly from simple discrete species to complicated supramolecular networks depending on the nature of metal ion, ligand substituents, stoichiometry, and with the presence of additional components [21, 22].
On the other hand, the use of carboxylates can generate a large number of coordination polymeric complexes composed of chains, sheets, and 3D networks with an enormous variety of intriguing structural topologies [23-30]. Such systems have received considerable attention due to their fascinating properties as well as their potential applications in many fields. However, the hydroxyl polycarboxylates (HPCs) such as malate and tartrate have less been studied as building blocks in the construction of MOFs though they can display versatile coordination modes $[29,30]$. In contrast to the aliphatic dicarboxylate compounds, the presence of the hydroxyl group in HPCs mostly allows the formation of fiveand six-member rings which can stabilize the solid networks [31]. In particular, the naturally existing chiral L-malic acid $\left(\mathrm{H}_{3} \mathrm{~L}-\mathrm{MA}\right)$ ligand, besides two terminal carboxyl groups, contains a hydroxyl group which can potentially provide an additional coordination site. In most of the malate-bridged $\mathrm{CPs}$, the oxygen atoms of the alkoxy or hydroxyl groups participate in coordination along with the $\alpha$-carboxyl and/or $\beta$-carboxyl groups. In addition, being an important biological 
ligand, $\mathrm{H}_{3} \mathrm{~L}-\mathrm{MA}$ has been found to have versatile coordination behaviour. Structurally characterized metal complexes of $\mathrm{H}_{3} \mathrm{~L}-\mathrm{MA}$ include monomers [32], dimers [33], and polymeric chain complexes [34], as well as 3D coordination polymers [35].

Moreover, only a little attention has been drawn on the coordination chemistry of metal complexes with $\mathrm{H}_{3} \mathrm{~L}-\mathrm{MA}$ ligand recently. And also, to the best of our knowledge, no attempts were made to synthesize calcium coordination polymers of $\mathrm{H}_{3} \mathrm{~L}-\mathrm{MA}$. With the previous background in mind, herein, we reported the synthesis, characterization, crystal structure, and photoluminescence properties of a new $\mathrm{Ca}(\mathrm{II})$ coordination polymer, $[\mathrm{Ca}(\mathrm{HL}-\mathrm{MA})]_{n}$.

\section{Material and Methods}

2.1. General. All chemicals were obtained from commercial sources and were used without further purification. Elemental analyses are performed on a PE-2400 CHN Elementar analyzer instrument. Reflectance UV-Vis spectra were recorded by Jasco V-630 spectrophotometer. Emission spectra were measured by Jasco F-4500 spectrofluorometer. Thermogravimetric analyses (TGA) were carried out using a DuPont TA Q50 analyzer on powder samples under flowing nitrogen gas with a heating rate of $10^{\circ} \mathrm{C} / \mathrm{min}$. Infrared (IR) spectra were recorded in the range of $400-4000 \mathrm{~cm}^{-1}$ on a JASCO FT/IR-4200 spectrophotometer by using KBr disks. Powder X-ray diffraction (PXRD) patterns were recorded on a Panalytical PW3040/60 diffractometer. Mercury (version 2.4) software has been used for the simulation of theoretical peaks using single-crystal X-ray diffraction data for PXRD measurement.

2.2. Synthesis of $[\mathrm{Ca}(H \mathrm{~L}-\mathrm{MA})]_{n} \cdot \mathrm{H}_{3} \mathrm{~L}-\mathrm{MA} \quad(0.0804 \mathrm{~g}$, $0.6 \mathrm{mmol}), \mathrm{Ca}\left(\mathrm{NO}_{3}\right)_{2} \cdot 4 \mathrm{H}_{2} \mathrm{O}(0.2361 \mathrm{~g}, 1.0 \mathrm{mmol}), \mathrm{EtOH}$ $(5.0 \mathrm{~mL})$, and $\mathrm{H}_{2} \mathrm{O}(3.0 \mathrm{~mL})$ were placed in a in $23 \mathrm{~mL}$ Teflon-lined digestion bombs and stirred for $20 \mathrm{~min}$ at room temperature. The reaction mixture turned into homogenous solution with the $\mathrm{pH}$ value of 2.32 . Then, the solvothermal reaction was carried out by heating the reaction mixture to $180^{\circ} \mathrm{C}$ for 2 days under autogenous pressure followed by slow cooling at the rate of $6^{\circ} \mathrm{C} \mathrm{h}^{-1}$ to room temperature. The colorless single crystals were collected in $79.38 \%(0.082 \mathrm{~g})$ yield on the basis of $\mathrm{H}_{3} \mathrm{~L}-\mathrm{MA}$. Elemental Analysis: Found (calculated) (\%) for $\mathrm{C}_{4} \mathrm{H}_{4} \mathrm{CaO}_{5}$ : C, 27.78 (27.91); $\mathrm{H}, 2.30$ (2.34). Reflectance UV-Vis: $\lambda_{\max }(\mathrm{nm}): 212,299,409$. IR: $\nu_{\max }$ $\left(\mathrm{cm}^{-1}\right)$ : $3604(\mathrm{w}), 3456(\mathrm{w}), 3212(\mathrm{w}), 2982(\mathrm{w}), 2907(\mathrm{w})$, 2820 (w), 2704 (w), 1564 (s), 1438 (s), 1398 (s), 1340 (w), 1307 (w), $1201(\mathrm{~m}), 1107(\mathrm{~m}), 1046(\mathrm{~m}), 964(\mathrm{w}), 934(\mathrm{w}), 897(\mathrm{w})$, $809(\mathrm{w}), 681(\mathrm{~s}), 620(\mathrm{~m}), 531(\mathrm{~m}), 484(\mathrm{~m}), 406(\mathrm{w})$.

2.3. Crystal Structure Determination. Single-crystal X-ray diffraction data for the complex was collected on Bruker AXS KAPPA APEX II diffractometer. All data were corrected for Lorentz and polarization effects, and the program SADABS in APEX2 was used for the absorption correction [36, 37]. While the hydrogen atoms bound to carbon were placed in idealized positions, the hydrogen atoms bound to other atoms were
TABLE 1: Crystallographic data for the complex.

\begin{tabular}{|c|c|}
\hline & Complex \\
\hline Formula & $\mathrm{C}_{4} \mathrm{H}_{4} \mathrm{CaO}_{5}$ \\
\hline Formula weight & 172.15 \\
\hline Space group & $P 2_{1} 2_{1} 2_{1}$ \\
\hline$a(\AA)$ & $6.7256(4)$ \\
\hline$b(\AA)$ & $7.0259(5)$ \\
\hline$c(\AA)$ & $10.5577(7)$ \\
\hline$\alpha\left(^{\circ}\right)$ & 90 \\
\hline$\beta\left(^{\circ}\right)$ & 90 \\
\hline$\gamma\left({ }^{\circ}\right)$ & 90 \\
\hline Volume $\left(\AA^{3}\right)$ & $619.75(2)$ \\
\hline$Z$ & 4 \\
\hline$D_{\text {cacl }},\left(\mathrm{g} \mathrm{cm}^{-3}\right)$ & 1.845 \\
\hline$\mu\left(\mathrm{mm}^{-1}\right)$ & 0.969 \\
\hline$T\left({ }^{\circ} \mathrm{C}\right)$ & $296(2)$ \\
\hline$\lambda(\AA)$ & 0.71073 \\
\hline Reflections collected & 4645 \\
\hline Independent reflections & 1531 \\
\hline$R$ (int) & 0.0215 \\
\hline Flack parameter & $0.03(3)$ \\
\hline Goodness-of-fit on $F^{2}$ & 1.055 \\
\hline$R_{1}[I>2 \sigma(I)]$ & 0.0228 \\
\hline$w R_{2}[I>2 \sigma(I)]$ & 0.0539 \\
\hline$R_{1}$ (all data) & 0.0252 \\
\hline$w R_{2}$ (all data) & 0.0549 \\
\hline CCDC no. & 806001 \\
\hline
\end{tabular}

TABLE 2: Selected bond lengths ( $\AA$ ) for the complex.

\begin{tabular}{ll}
$\mathrm{Ca}(1)-\mathrm{O}(5)$ & 2.2974 \\
$\mathrm{Ca}(1)-\mathrm{O}(1)^{\# 1}$ & 2.3452 \\
$\mathrm{Ca}(1)-\mathrm{O}(2)^{\# 2}$ & 2.3473 \\
$\mathrm{Ca}(1)-\mathrm{O}(4)^{\# 3}$ & 2.3625 \\
$\mathrm{Ca}(1)-\mathrm{O}(3)^{\# 3}$ & 2.3851 \\
$\mathrm{Ca}(1)-\mathrm{O}(2)^{\# 4}$ & 2.4242 \\
$\mathrm{Ca}(1)-\mathrm{O}(1)^{\# 4}$ & 2.6222 \\
\hline
\end{tabular}

Symmetry transformations used to generate equivalent atoms: for complex, no. $1: x-1 / 2,-y+1 / 2,-z+1$; no. $2: x+1 / 2,-y+1 / 2,-z+1$; no. $3:-x+$ $1 / 2,-y+1, z-1 / 2$; no. $4: x, y+1, z$.

located from the difference Fourier map and were set riding on the parent atom with idealized distances. All nonhydrogen 


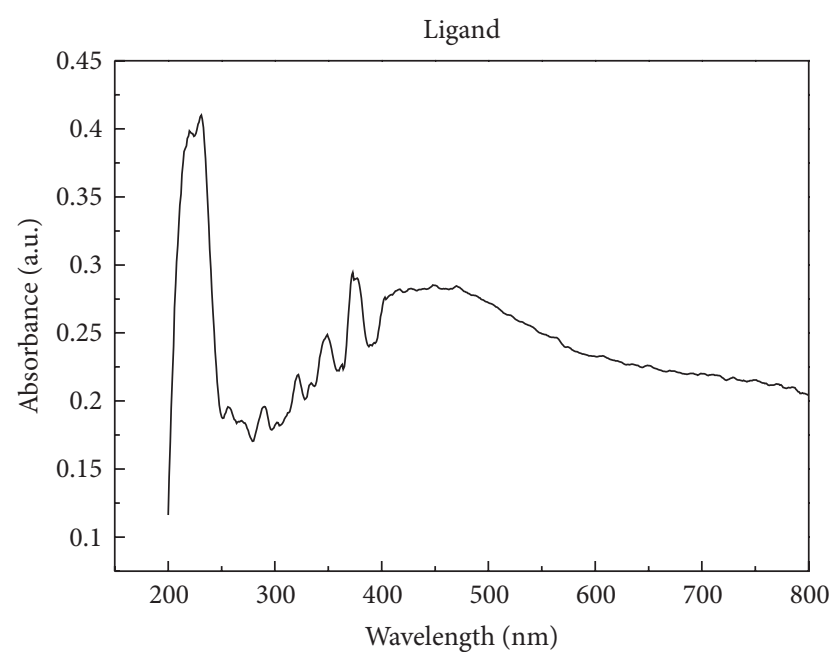

(a)

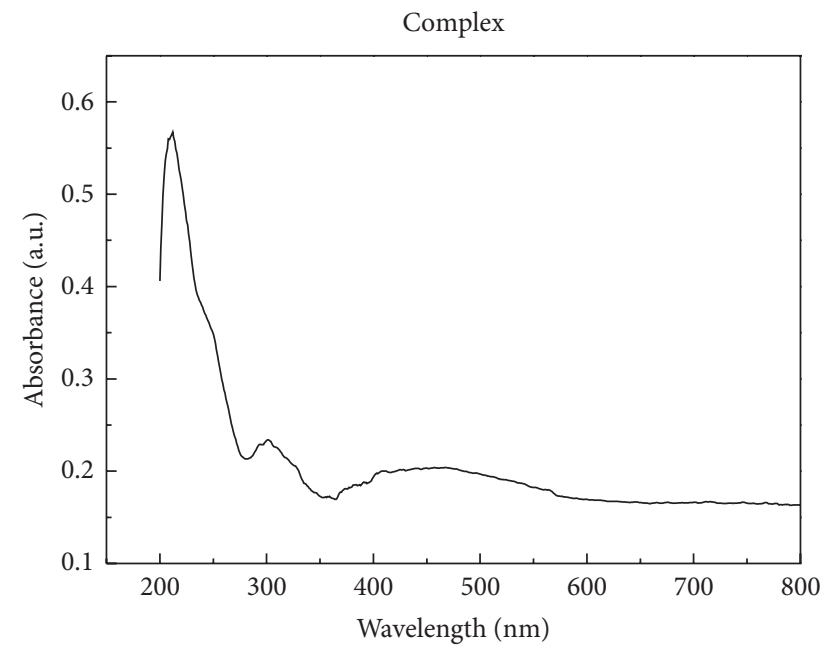

(b)

FIGURE 1: UV-Vis absorption spectra for the ligand and the complex.

atoms were refined with anisotropic thermal parameters. All the structures were refined (weighted least squares refinement on $F^{2}$ ) to convergence [38]. Relevant data concerning data collection and details of the structure refinements are summarized in Table 1 . Selected $\mathrm{Ca}-\mathrm{O}$ bond lengths are listed in Table 2.

\section{Results and Discussion}

3.1. Synthesis and Characterization. The complex has been synthesized as described in the experimental section using solvothermal reaction condition. A particular (3:5) $\mathrm{H}_{3} \mathrm{~L}-\mathrm{MA}$ and metal salt molar ratio has been used to prepare the complex. The complex is stable in air and insoluble in common organic solvents such as acetone, methanol, ethanol, dichloromethane, acetonitrile, chloroform, DMF, and DMSO. The elemental analysis results of the complex are in accorded with

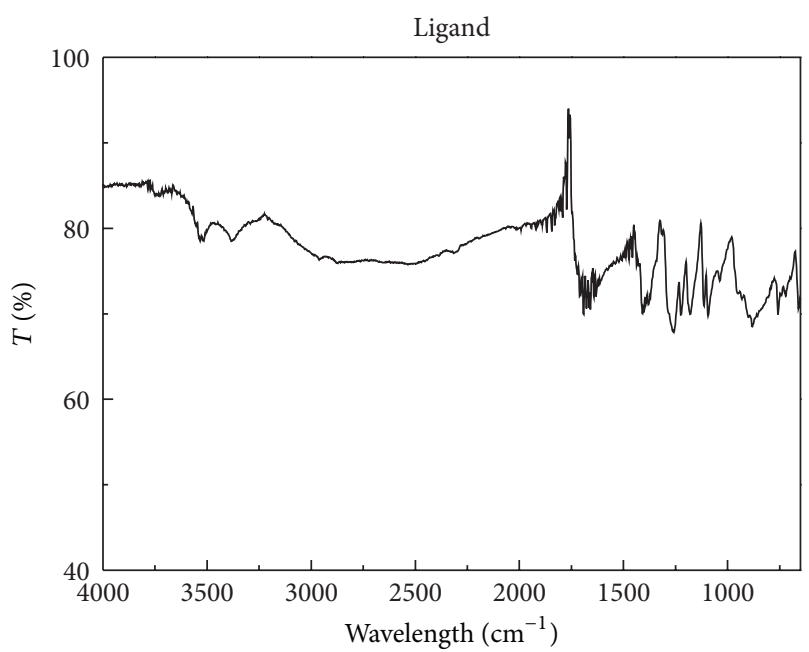

(a)

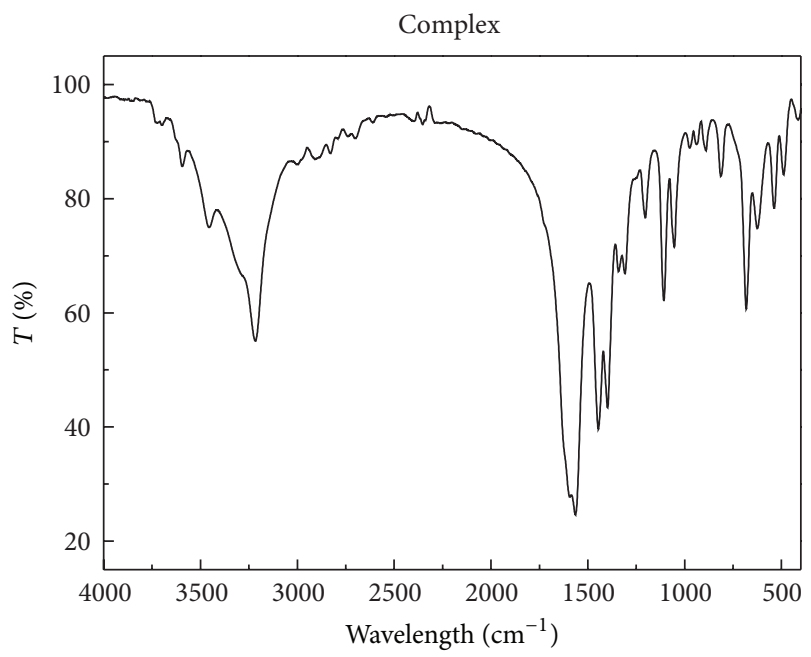

(b)

FIGURE 2: FT-IR spectra of $\mathrm{H}_{3} \mathrm{~L}-\mathrm{MA}$ and complex.

the theoretical values. The diffuse reflectance UV-Vis spectra at room temperature have been recorded for the ligand and the complex (Figure 1). On comparing the ligand spectra with the complex, the observed peaks for the complex are mainly due to the intraligand charge transfer transitions. The IR spectra of the ligand and the complex have been given in Figure 2. The IR peak shifts of the ligand in the complex gave an idea about its coordination behaviour. The exact polymeric structure of the new complex was finally confirmed by single crystal X-ray crystallographic studies.

3.2. Structural Description of $[\mathrm{Ca}(H L-M A)]_{n}$. Single-crystal $\mathrm{X}$-ray diffraction result shows that the structure of the complex possesses a 3D framework and crystallizes in the space group of $P 2_{1} 2_{1} 2_{1}$. The asymmetric unit of the complex consists of one independent $\mathrm{Ca}^{2+}$ ion and one HL-MA ligand unit. The independent $\mathrm{Ca}^{2+}$ ion center is seven-coordinated 


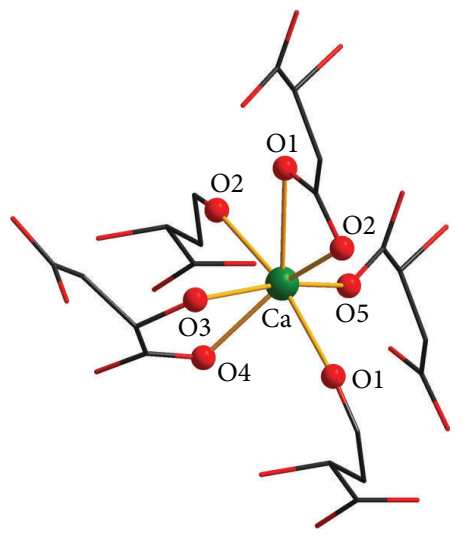

(a)

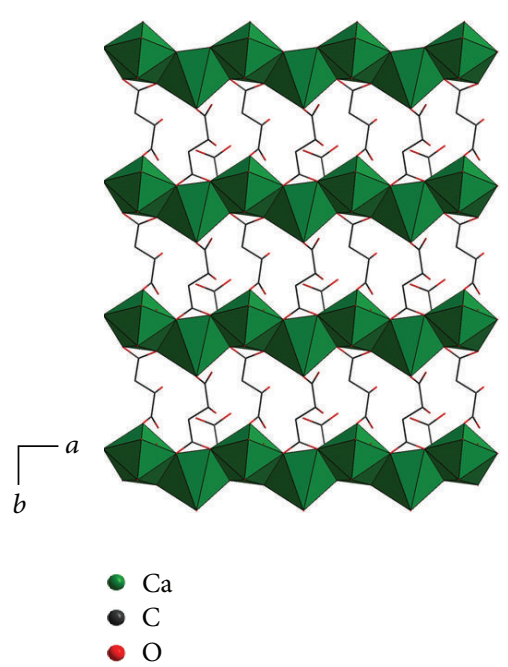

(c)

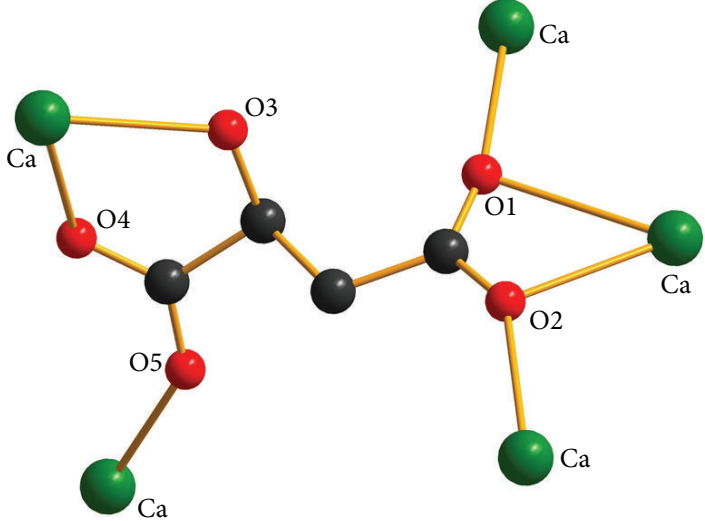

(b)

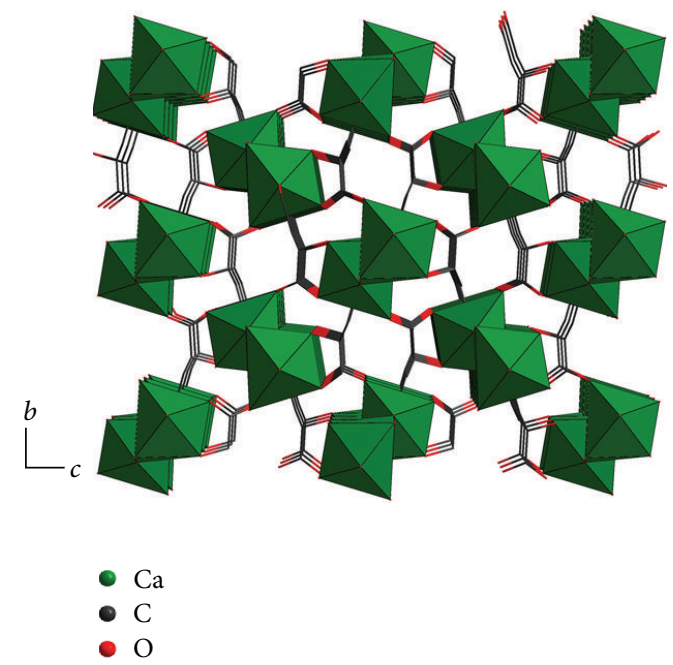

(d)

Figure 3: (a) The coordination spheres of calcium atom in the complex. (b) The coordination mode of the ligand in the complex. (c) The edge-sharing $2 \mathrm{D}$ layer in the complex. (d) The 3D network viewed along the $a$-axis ( $\mathrm{H}$ atoms were omitted for clarity).

and exhibits a distorted pentagonal bipyramidal geometry; $\mathrm{Ca}^{2+}$ is coordinated by two $\alpha$-carboxylate $\mathrm{O}$ atoms (O4 and O5) belonging to two HL-MA ligands, four $\beta$-carboxylate $\mathrm{O}$ atoms (O1, O1, O2, and $\mathrm{O} 2$ ) belonging to three HL-MA ligands, and one alkoxyl $\mathrm{O}$ atom $(\mathrm{O} 3)$ belonging to a similar HL-MA ligand mentioned for one of the two $\alpha$-carboxylate $\mathrm{O}$ atoms (Figure 3(a)). The ligand in the asymmetric unit has acted as dianionic heptadentate and coordinated to five $\mathrm{Ca}^{2+}$ ions (Figure 3(b)). The two of the coordinated $\beta$-carboxylate $\mathrm{O}$ atoms ( $\mathrm{O} 1$ and $\mathrm{O} 2)$ form bridge between two Ca centers. The typical $\mathrm{Ca}-\mathrm{O}$ bond distances range from 2.2974 (13) to 2.6222 (12) $\AA$ (Table 2). The participation of $\mathrm{O}$ atom (O3) of hydroxyl group (as neutral donor) in coordination along with the one $\alpha$-carboxyl group $\mathrm{O}$ atom (O4) of the ligand forms five-member chelation ring consisting of $\mathrm{Cal}, \mathrm{O} 4, \mathrm{C} 4, \mathrm{C} 3$, and $\mathrm{O} 3$ atoms in the complex. As shown in Figure 3(c), the $\mathrm{CaO}_{7}$ pentagonal bipyramidal motifs which are connected by coordinated $\beta$-carboxylate $\mathrm{O}$ atoms ( $\mathrm{O} 1$ and $\mathrm{O} 2)$ display a $1 \mathrm{D}$ zigzag chain in the complex. These $1 \mathrm{D}$ chains which are linked together by HL-MA ligands generate the 3D structure (Figure 3(d)).

3.3. Powder X-Ray Diffraction Analysis of the Complex. The purity and homogeneity of the bulk products of the complex has been determined by the comparison of simulated and experimental X-ray powder diffraction patterns. The peak positions of the experimental patterns for the complex nearly matched with the simulated one generated from singlecrystal X-ray diffraction data, as depicted in Figure 4 . The differences in intensity may be due to the preferred orientation of the powder samples.

3.4. Thermal Stability. The thermal stability of the complex has been studied using thermogravimetry analysis (TGA), 


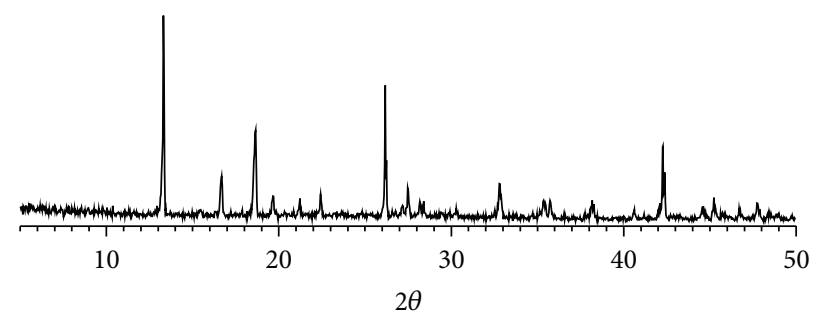

(a)

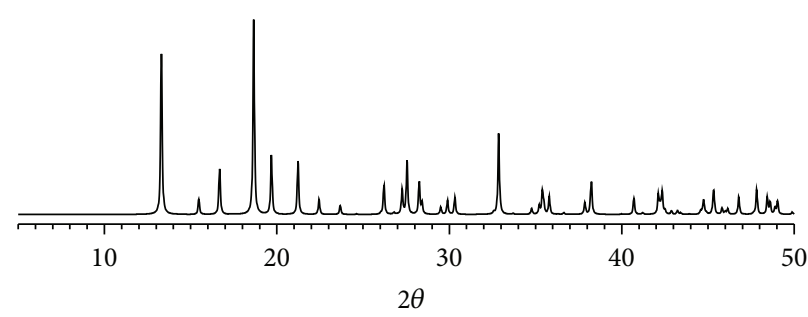

(b)

FIGURE 4: Powder XRD patterns of the complex (measured, (a); calculated, (b)).

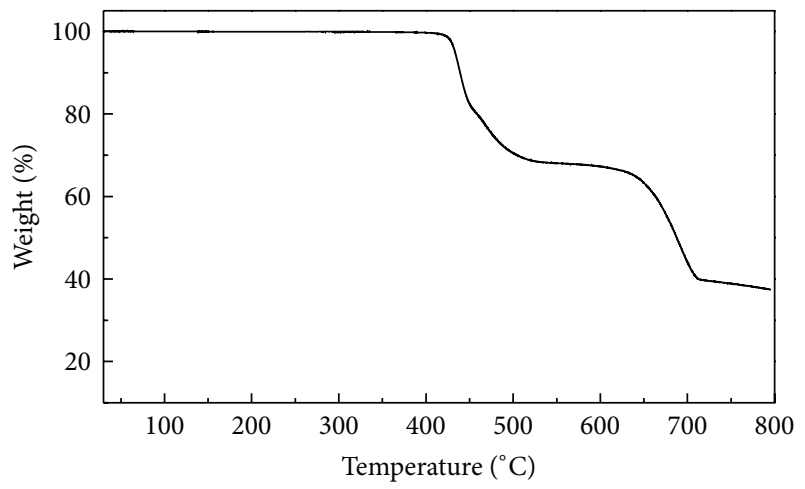

FIgURE 5: The TGA curve of the complex.

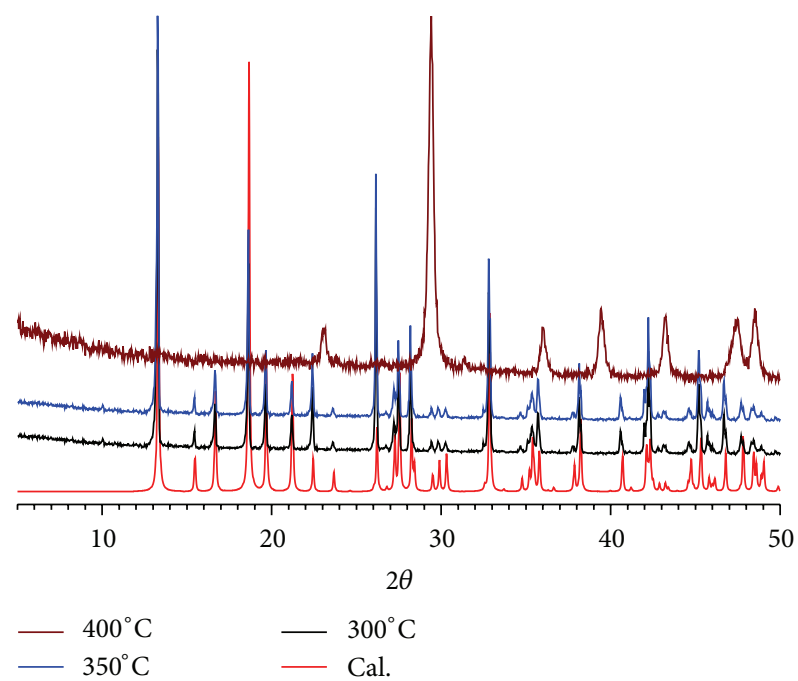

FIGURE 6: Powder XRD patterns of the complex at various temperatures.

and the TGA curves are given in Figure 5. TGA curve of the complex showed that the weight loss is observed only after $410^{\circ} \mathrm{C}$ which clearly indicated that the complex is very much stable up to $410^{\circ} \mathrm{C}$. The thermal stability of the complex has further been studied with aid of PXRD technique. The PXRD pattern of the complex at various temperatures confirmed once again the high thermal stability of the complex framework (Figure 6). That is, the PXRD pattern of the complex revealed that the complex is stable up to $350^{\circ} \mathrm{C}$. So, it is a rare example that one coordination polymeric complex has retained its original structure up to very high temperature like $350^{\circ} \mathrm{C}$. It is also to be noted that the TGA curve of the complex and the two weight losses $(62.5 \%)$ observed after $410^{\circ} \mathrm{C}$ suggested that the coordinated ligand started to decompose step by step upon increasing the temperature to $800^{\circ} \mathrm{C}$.

3.5. Photoluminescence Properties. The solid-state excitationemission spectra of the ligand and its alkaline earth metal complexes have been studied at room temperature, and their corresponding spectra are shown in Figure 7. The strongest emission peak for the free $\mathrm{H}_{3} \mathrm{~L}-\mathrm{MA}$ is at $416 \mathrm{~nm}$ with the excitation peak at $337 \mathrm{~nm}$. It is attributed to the $\pi^{*} \rightarrow n$ transitions [39]. Compared with the free ligand, the strongest emission peak for the complex is at $418 \mathrm{~nm}$, and its excitation spectrum mainly showed strong peak at $342 \mathrm{~nm}$. The emission spectrum of the new complex is much similar to that of the free ligand transitions and it may be ligand-centered electronic transition perturbed by the coordination to metal ions rather than to protons. These observations suggest that the new $\mathrm{Ca}$ (II) coordination polymer will be a candidate for potential photoactive material.

\section{Conclusion}

The present investigation demonstrated the structure and properties of a new calcium coordination polymer based on chiral L-malic acid ligand via solvothermal reaction. It is interesting to note that the complex exhibits 3D framework. The TGA and PXRD results revealed that the complex can retain its original framework structure up to $350^{\circ} \mathrm{C}$. It is also to be noted that the complex exhibited promising photoluminescence properties. The observed results are very much comparable with our previous report [40].

\section{Conflict of Interests}

The authors have declared that there is no conflict of interests. 


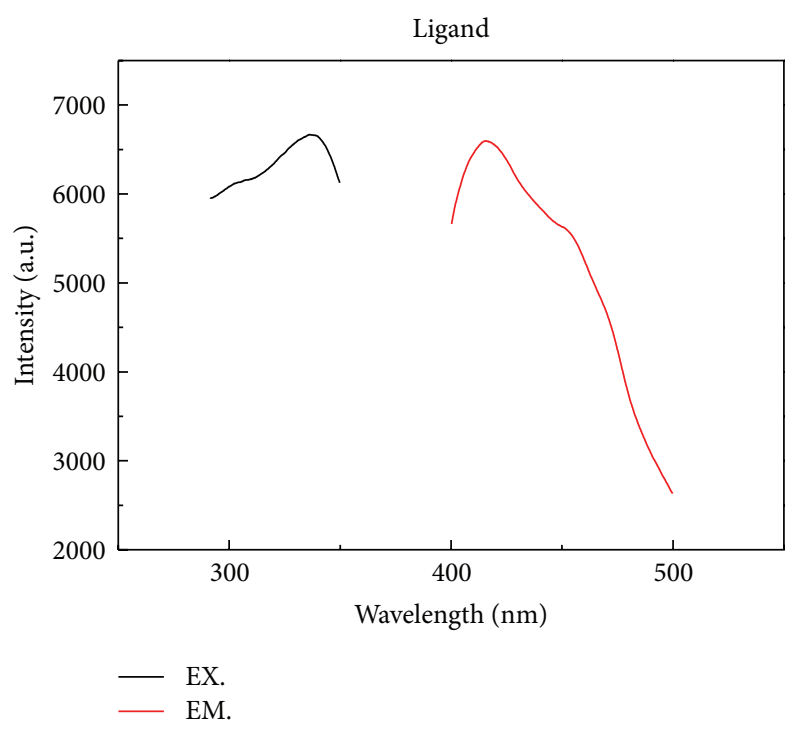

(a)

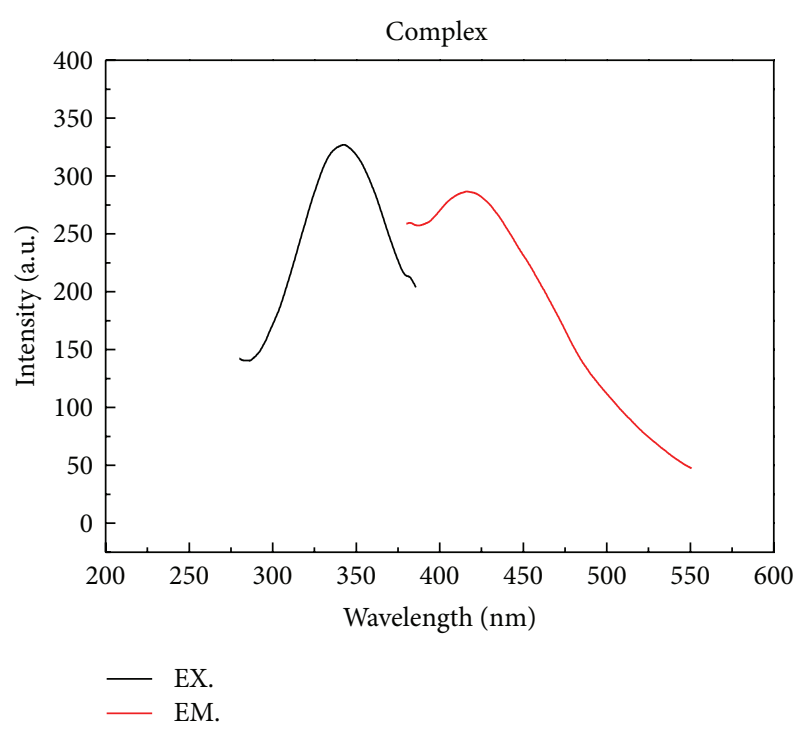

(b)

FIGURE 7: Photoluminescence emission spectra of the ligand and the complex.

\section{Acknowledgments}

Financial assistance received from the National Science Council, Taiwan (NSC101-2113-M-033-007-MY3 and NSC101-2811-M-033-018) is gratefully acknowledged. Acknowledgment is also made to Mrs. C.-W. Lu, Instrumentation Center, National Taiwan, University, Taiwan for her help in elemental analyses of the new complexes.

\section{References}

[1] O. M. Yaghi and H. Li, "Hydrothermal synthesis of a metalorganic framework containing large rectangular channels," Journal of the American Chemical Society, vol. 117, no. 41, pp. 10401-10402, 1995.

[2] A. Kamiyama, T. Noguchi, T. Kajiwara, and T. Ito, "A graphitelike complex with large cavities constructed with the complex ligand $\left[\mathrm{NiII}(\mathrm{bpca})_{2}\right.$ ]," Angewandte Chemie International Edition, vol. 39, pp. 3130-3132, 2000.

[3] K. Uemura, S. Kitagawa, M. Kondo et al., "Novel flexible frameworks of porous cobalt(II) coordination polymers that show selective guest adsorption based on the switching of hydrogenbond pairs of amide groups," Chemistry: A European Journal, vol. 8, pp. 358-3600, 2002.

[4] J. R. Li, Y. Ma, M. C. McCarthy et al., "Carbon dioxide capturerelated gas adsorption and separation in metal-organic frameworks," Coordination Chemistry Reviews, vol. 255, no. 15-16, pp. 1791-1823, 2011.

[5] N. L. Rosi, J. Eckert, M. Eddaoudi et al., "Hydrogen storage in microporous metal-organic frameworks," Science, vol. 300, no. 5622, pp. 1127-1129, 2003.

[6] S. Ma, J. A. Fillinger, M. W. Ambrogio, J. L. Zuo, and H. C. Zhou, "Synthesis and characterizations of a magnesium metal-organic framework with a distorted $(10,3)$-a-net topology," Inorganic Chemistry Communications, vol. 10, no. 2, pp. 220-222, 2007.
[7] Y. Tan, Z. Fu, and J. Zhang, "A layered amino-functionalized zinc-terephthalate metal organic framework: structure, characterization and catalytic performance for Knoevenagel condensation," Inorganic Chemistry Communications, vol. 14, pp. 19661970, 2011.

[8] Z.-H. Li, L.-P. Xue, L. Wang, S.-T. Zhang, and B.-T. Zhao, "Two-dimensional copper-based metal-organic framework as a robust heterogeneous catalyst for theN-arylation of imidazole with arylboronic acids," Inorganic Chemistry Communications, vol. 27, pp. 119-121, 2013.

[9] L. Ma, C. Abney, and W. Lin, "Enantioselective catalysis with homochiral metal-organic frameworks," Chemical Society Reviews, vol. 38, no. 5, pp. 1248-1256, 2009.

[10] Z. Jin, H. Zhao, D. Yang, X. Yao, and G. Zhu, "A novel 3D porous cadmium(II) MOF based on conjugated ligand with potential application for sensing small linear conjugated molecule," Inorganic Chemistry Communications, vol. 25, pp. 74-78, 2012.

[11] B. Chen, S. Xiang, and G. Qian, "Metal-organic frameworks with functional pores for recognition of small molecules," Accounts of Chemical Research, vol. 43, no. 8, pp. 1115-1124, 2010.

[12] C. Qi, D. Zhang, S. Gao et al., "Crystal structure and magnetic property of a metal-organic framework (MOF) containing double-stranded chain with metallomacrocycles and dinuclear Mn(II) subunits," Journal of Molecular Structure, vol. 891, no. 13, pp. 357-363, 2008.

[13] L. Zhao, G. F. Xu, and J. Tang, "Carboxylato-bridged 3D polymeric networks of $\operatorname{Pr}(\mathrm{III})$ : synthesis, crystal structure, magnetic property and thermal behavior," Journal of Molecular Structure, vol. 979, no. 1-3, pp. 160-164, 2010.

[14] C. Wang, G. Guo, and P. Wang, "Two sodium and lanthanide(III) MOFs based on oxalate and V-shaped 4,4'oxybis(benzoate) ligands: hydrothermal synthesis, crystal structure, and luminescence properties," Journal of Molecular Structure, vol. 1032, pp. 93-99, 2013. 
[15] R. Wang, J. Zhang, and L. Li, "A 2D metal-organic framework with a flexible cyclohexane-1,2,5,6-tetracarboxylic acid ligand: synthesis, characterization and photoluminescent property," Journal of Molecular Structure, vol. 970, no. 1-3, pp. 14-18, 2010.

[16] D. J. Zhang, T. Y. Song, P. Zhang et al., "Solvothermal synthesis, crystal structure and photoluminescent property of a novel 3-D magnesium metal-organic framework $\mathrm{Mg}_{1.5}(\mu 5$-btec $\left.)\left(\mathrm{H}_{2} \mathrm{O}\right)_{2}\right]$. $\left[\mathrm{H}_{2} \mathrm{~N}\left(\mathrm{CH}_{3}\right)_{2}\right] \cdot \mathrm{H}_{2} \mathrm{O}$," Inorganic Chemistry Communications, vol. 10, no. 8, pp. 876-879, 2007.

[17] P. Horcajada, C. Serre, M. Vallet-Regí, M. Sebban, F. Taulelle, and G. Férey, "Metal-organic frameworks as efficient materials for drug delivery," Angewandte Chemie International Edition, vol. 45, no. 36, pp. 5974-5978, 2006.

[18] A. Mesbah, C. Juers, F. Lacouture et al., "Inhibitors for magnesium corrosion: metal organic frameworks," Solid State Sciences, vol. 9, no. 3-4, pp. 322-328, 2007.

[19] A. Shigematsu, T. Yamada, and H. Kitagawa, "Wide control of proton conductivity in porous coordination polymers," Journal of the American Chemical Society, vol. 133, no. 7, pp. 2034-2036, 2011.

[20] H. Kitagawa, Y. Nagao, M. Fujishima, R. Ikeda, and S. Kanda, "Highly proton-conductive copper coordination polymer, $\mathrm{H}_{2}$ dtoa $\mathrm{Cu}\left(\mathrm{H}_{2}\right.$ dtoa = dithiooxamide anion)," Inorganic Chemistry Communications, vol. 6, no. 4, pp. 346-348, 2003.

[21] V. Chandrasekhar, S. Nagendran, and V. Baskar, "Organotin assemblies containing Sn-O bonds," Coordination Chemistry Reviews, vol. 235, no. 1-2, pp. 1-52, 2002.

[22] C. P. Li and M. Du, "Role of solvents in coordination supramolecular systems," Chemical Communications, vol. 47, no. 21, pp. 5958-5972, 2011.

[23] F. Guo, F. Wang, H. Yang, X. Zhang, and J. Zhang, “Tuning structural topologies of three photoluminescent metal-organic frameworks via isomeric biphenyldicarboxylates," Inorganic Chemistry, vol. 51, pp. 9677-9682, 2012.

[24] W. Gao, F. Xing, D. Zhou, M. Shao, and S. Zhu, "Novel MOFs with tetrahedral cavity assembled from $4,4^{\prime}, 4$ " $-s$-triazine-2,4,6triyltribenzoic acid ( $\mathrm{H}_{3}$ TATB)," Inorganic Chemistry Communications, vol. 14, no. 4, pp. 601-605, 2011.

[25] J. Xie, Z. Han, W. Pei, Y. Zou, and X. Ren, “Organic heterocycleaffecting the structural variability of $\mathrm{Cd}(\mathrm{II})$-btc coordination polymers $\left(\mathrm{H}_{3}\right.$ btc = benzene-1,3,5-tricarboxylic acid)," Inorganic Chemistry Communications, vol. 14, no. 8, pp. 1266-1270, 2011.

[26] Q. Sun, A.-L. Cheng, Y.-Q. Wang, Y. Ma, and E.-Q. Gao, "Magnetic ordering in three-dimensional metal-organic frameworks based on carboxylate bridged square-grid layers," Inorganic Chemistry, vol. 50, pp. 8144-8152, 2011.

[27] H.-L. Gao, C.-C. Hu, H. Zhang, H.-T. Wang, A.-H. Yang, and J.-Z. Cui, "Three polymers based on pyridine-2,3,5,6-tetracarboxylic acid: syntheses, crystal structures and luminescent properties," Inorganic Chemistry Communications, vol. 23, pp. 9-13, 2012.

[28] X. Ouyang, Z. Chen, X. Liu et al., "One-dimensional (1D) helical and $2 \mathrm{D}$ homochiral metal-organic frameworks built from a new chiral octahydrobinaphthalene-derived dicarboxylic acid," Inorganic Chemistry Communications, vol. 11, no. 9, pp. 948950, 2008.

[29] J. Lu, J. H. Yu, X. Y. Chen, P. Cheng, X. Zhang, and J. Q. Xu, "Novel self-assembled chain of water molecules in a metalorganic framework structure of $\mathrm{Co}(\mathrm{II})$ with tartrate acid," Inorganic Chemistry, vol. 44, no. 17, pp. 5978-5980, 2005.
[30] Z. Amghouz, L. Roces, S. García-Granda et al., "Metal organic frameworks assembled from $\mathrm{Y}(\mathrm{III}), \mathrm{Na}(\mathrm{I})$, and chiral flexibleachiral rigid dicarboxylates," Inorganic Chemistry, vol. 49, no. 17, pp. 7917-7926, 2010.

[31] M.-L. Hu, A. Morsali, and L. Aboutorabi, "Lead(II) carboxylate supramolecular compounds: coordination modes, structures and nano-structures aspects," Coordination Chemistry Reviews, vol. 255, pp. 282-2859, 2011.

[32] Z. H. Zhou, G. F. Wang, S. Y. Hou, H. L. Wan, and K. R. Tsai, "Tungsten-malate interaction. Synthesis, spectroscopic and structural studies of homochiral S-malato tungstate(VI), $\Lambda$ $\mathrm{Na}_{3}\left[\mathrm{WO}_{2} \mathrm{H}(\mathrm{S}-\mathrm{mal})_{2}\right]$," Inorganica Chimica Acta, vol. 314, no. 12, pp. 184-188, 2001.

[33] M. Kaliva, T. Giannadaki, A. Salifoglou, C. P. Raptopoulou, A. Terzis, and V. Tangoulis, "pH-dependent investigations of vanadium(V)-peroxo-malate complexes from aqueous solutions. In search of biologically relevant vanadium $(\mathrm{V})$-peroxo species," Inorganic Chemistry, vol. 40, no. 15, pp. 3711-3718, 2001.

[34] A. Karipides and A. T. Reed, "Stereochemistry of carboxylate complexes. Crystal structure of (-)589malatodiaquomanganese(II) hydrate," Inorganic Chemistry, vol. 15, no. 1, pp. 44-47, 1976.

[35] N. Lah, I. K. Cigić, and I. Leban, "Solvothermal synthesis of a novel mixed valence $\mathrm{Cu}(\mathrm{I}) / \mathrm{Cu}(\mathrm{II})$ complex containing sulphate, malate and 4,4' -bipyridine, $\left[\mathrm{Cu}^{\mathrm{I}} \mathrm{Cu}_{2}^{\mathrm{II}}(\mathrm{mal})\left(\mathrm{SO}_{4}\right)(\text { bpy })_{2} \cdot \mathrm{H}_{2} \mathrm{O}\right]_{2}$. Unique binding mode of the malate anion," Inorganic Chemistry Communications, vol. 6, no. 12, pp. 1441-1444, 2003.

[36] APEX2, Program for Data Collection on Area Detectors, BRUKER AXS Inc., Madison, Wis, USA.

[37] SADABS and G. M. Sheldrick, Program For Absorption Correction of Area Detector Frames, BRUKER AXS Inc., Madison, Wis, USA.

[38] G. M. Sheldrick, "A short history of SHELX," Acta Crystallographica Section A, vol. 64, no. 1, pp. 112-122, 2007.

[39] W. Chen, J. Y. Wang, C. Chen et al., "Photoluminescent metalorganic polymer constructed from trimetallic clusters and mixed carboxylates," Inorganic Chemistry, vol. 42, no. 4, pp. 944-946, 2003.

[40] P.-C. Cheng, F.-S. Tseng, C.-T. Yeh et al., "Synthesis, structures, and properties of alkali and alkaline earth coordination polymers based on V-shaped ligand," CrystEngComm, vol. 14, pp. 6812-6822, 2012. 

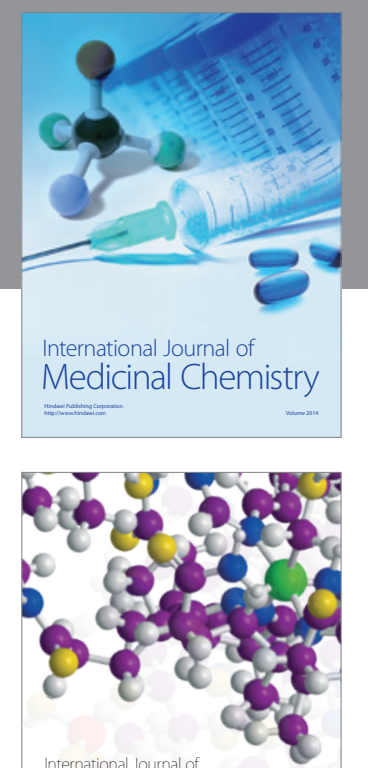

\section{Carbohydrate} Chemistry

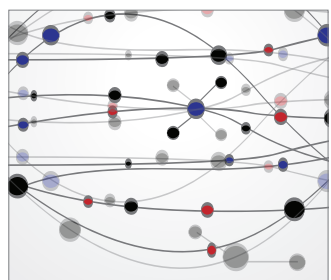

The Scientific World Journal
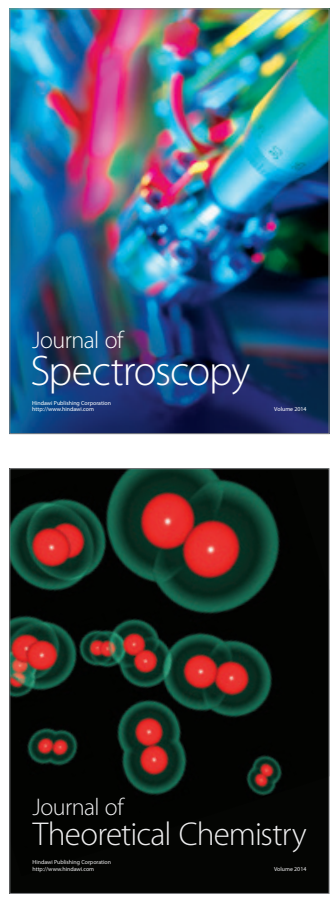
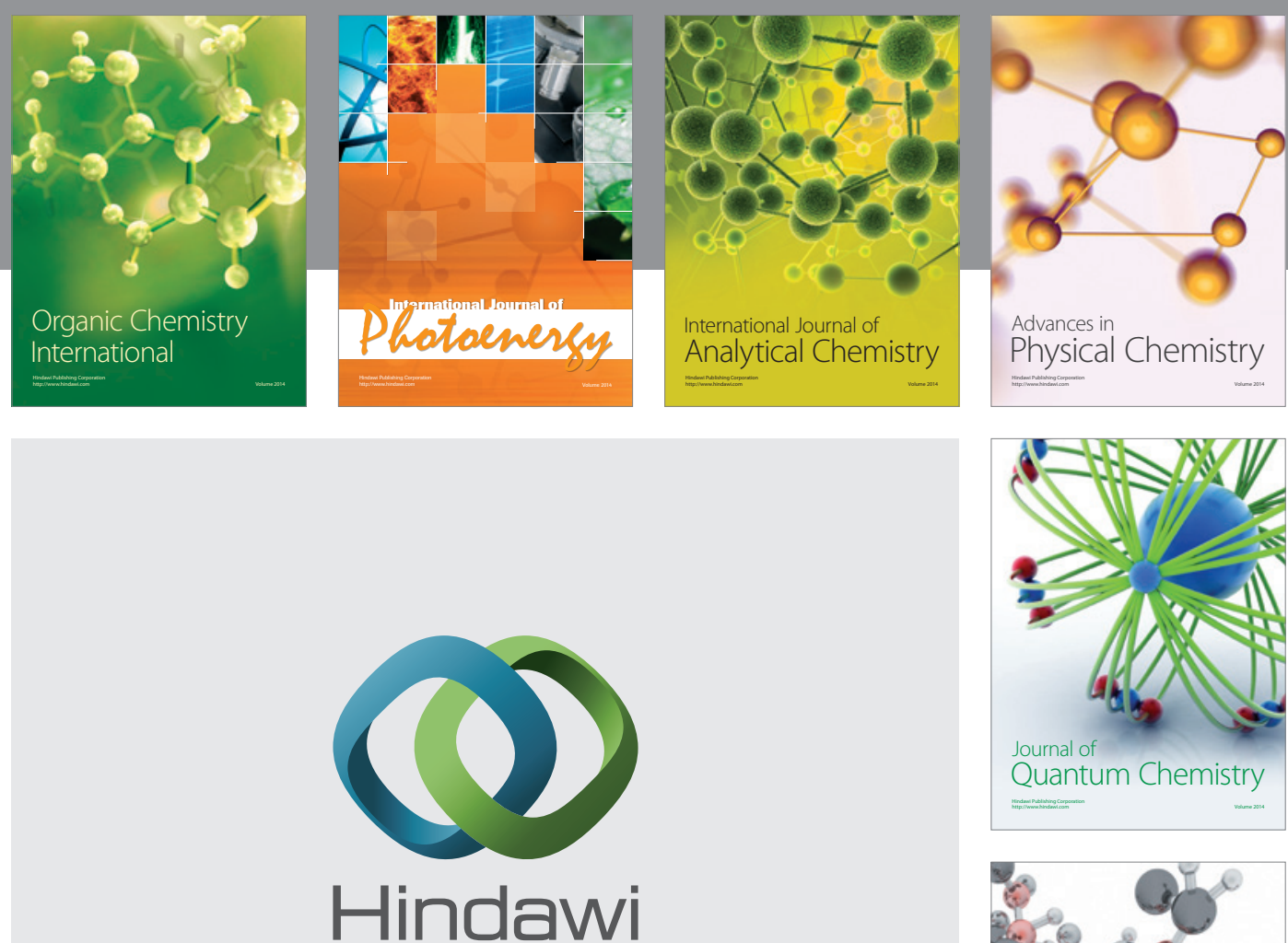

Submit your manuscripts at

http://www.hindawi.com

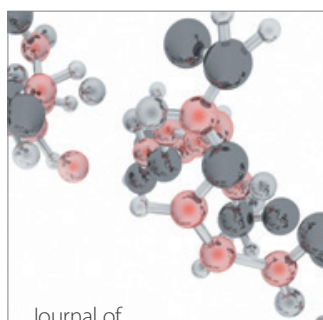

Analytical Methods

in Chemistry

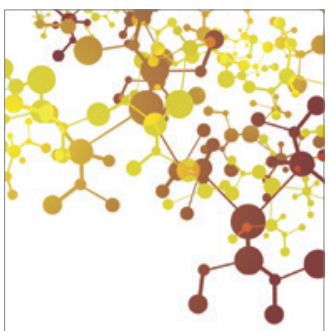

Journal of

Applied Chemistry

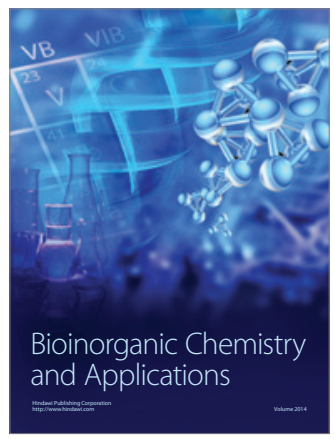

Inorganic Chemistry
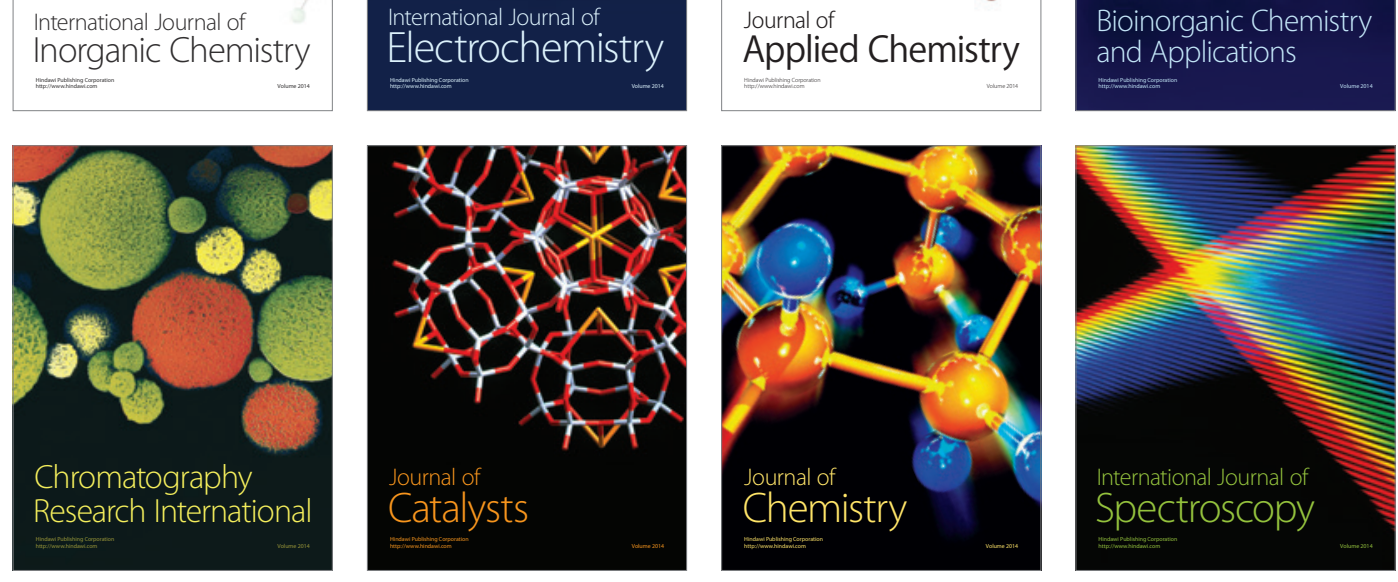